\title{
Genetic testing for asthma
}

\author{
G.H. Koppelman*, G.J. te Meerman ${ }^{\#}$ and D.S. Postma
}

ABSTRACT: Asthma is a genetically complex disease caused by multiple genetic and environmental factors. An increasing number of asthma susceptibility genes are currently being identified. The present study addresses the question as to whether this genetic information can be used to predict asthma, particularly in pre-school children.

The predictive value of a single gene test in a complex disease is very limited for diagnostic or preventive purposes and thus cannot be recommended. Based on data of simulation studies and other complex diseases, the use of genetic profiling that incorporates multiple genetic risk factors holds promise for clinical application. The results of genome-wide association studies will be crucial in establishing this genetic risk profile for asthma.

In the future, asthma prediction may be possible, based on a prediction model that incorporates genes, personal factors and environmental risk factors. Studies in general and at-risk populations are needed to investigate and validate this approach.

KEYWORDS: Asthma, gene, genome-wide association, prediction, testing

A sthma is a chronic inflammatory disease of the airways, characterised by respiratory symptoms such as wheezing, breathlessness, intermittent airway obstruction and airway hyperresponsiveness. Asthma is the result of the interaction of multiple genetic and environmental factors [1].

Over the last 15 yrs, significant progress has been made in genetic studies of asthma using candidate gene and positional cloning studies and, most recently, genome-wide association (GWA) studies. In $\geqslant 10$ populations, 10 candidate genes for asthma susceptibility or severity have been replicated. These genes encode interleukin (IL)4, IL4 receptor- $\alpha$ chain (IL4RA), IL13, $\beta 2$ adrenergic receptor, human leukocyte antigen (HLA)-DRB1 and $D Q B 1$, tumour necrosis factor- $\alpha$, lymphotoxin- $\alpha$, the $\beta$-chain of the high-affinity immunoglobulin $E$ receptor, $C D 14$, and $A$ disintegrin and matrix metalloprotease-33 (ADAM33) [2].

Seven asthma genes have been discovered through positional cloning, a technique based on the identification of chromosomal regions that are linked with asthma in families. Subsequent detailed analyses of genes within this chromosomal region can reveal potential novel genes for asthma. The first of these genes, ADAM33 [3], has been shown to be important in susceptibility to asthma and bronchial hyperresponsiveness in multiple populations [2]. Other novel identified genes, such as those encoding dipeptidylpeptidase 10 [4], PHD finger protein 11 [5], SFRS8 [6], CYF1P2 [7] and HLA-G [8], are currently subject to replication studies. If these genes are confirmed in other populations, as recently shown for the gene encoding G-protein coupled receptor A (Neuropeptide $S$ receptor-1) [7, 9-11], new insights into the pathogenesis of asthma will be obtained in the future.

One novel asthma gene has recently been identified through GWA studies. In GWA studies, the complete genome is scanned using a chip with 317,000-1,000,000 single nucleotide polymorphisms (SNPs) and significant allele frequency differences between asthma cases and controls are investigated. MofFATT et al. [12] have identified a sequence variant on chromosome $17 \mathrm{q}$ that is associated with ORMDL3 expression to be significantly associated with childhood asthma. This finding has now been replicated in two populations $[13,14]$.

In addition to genetic factors, personal factors, such as sex and age, and environmental factors are important in asthma development (table 1). The increase in the prevalence of asthma over the last $20 \mathrm{yrs}$ can't be explained by the small changes in the genetic constitution of the Western population that occur over time, but by the changing environment. Different environmental factors, such as indoor and outdoor
AFFILIATIONS

*Dept of Paediatric Pulmonology and Paediatric Allergology, Beatrix Children's Hospital, Depts of ${ }^{\#}$ Genetics and "Pulmonology, University Medical Center Groningen, University of Groningen, Groningen, The Netherlands.

CORRESPONDENCE

G.H. Koppelman

Dept of Paediatric Pulmonology and Paediatric Allergology

Beatrix Children's Hospital

University Medical Center Groningen University of Groningen

P0 Box 30.001

9700 RB Groningen

The Netherlands

Fax: 31503614235

E-mail: g.h.koppelman@

bkk.umcg.nl

Received:

June 192008

Accepted after revision:

June 222008

\section{SUPPORT STATEMENT}

G.H. Koppelman was supported by The Netherlands Organisation for Health Research and Development (grant 916.56.091)

\section{STATEMENT OF INTEREST}

None declared.

European Respiratory Journal Print ISSN 0903-1936 Online ISSN 1399-3003 
pollution, allergen exposure, tobacco smoke and other factors related to the "Western lifestyle" like contact with microbial products, may be implicated in asthma pathogenesis [15, 16].

It is unknown if these genetic, environmental or personal risk factors act independently or in interaction with each other in the development of asthma. More studies are needed to characterise the interaction of multiple genes and multiple environmental factors. These investigations are complicated by the fact that large sample sizes are needed [17].

The identification of the genetic basis of asthma opens up avenues for the clinical application of this knowledge. The present review will discuss the possibilities of applying genetic information to the prediction of asthma, with a specific focus on early childhood asthma. The latter focus is based on the assumption that it is likely that gene-environment interactions in early life contribute to the development of asthma and that primary preventive approaches will be specifically targeted in this age group. Moreover, up to $40 \%$ of children in early childhood have chronic respiratory symptoms. It is a real challenge for clinicians to identify children who will develop chronic asthma. Currently, use of easy applicable, noninvasive tests that are not time consuming to study bronchial hyperresponsiveness or lung function, phenotypes crucial to an objective diagnosis of asthma, are lacking in clinical practice for preschool children. Thus, genetic profiling may open new areas of investigation to identify children at risk.

Before discussing the application of genetic tests in asthma, the current status of genetic research in asthma and the prediction of asthma in childhood will be examined.

\section{GENETICS OF ASTHMA: CURRENT STATUS}

Asthma is a genetically complex disease. In contrast to monogenic Mendelian diseases, no one-to-one relationship between the gene and the disease exists, which may be due to incomplete penetrance (i.e. subjects with the disease gene variants but without the disease), phenocopies (subjects with asthma but without a genetic cause) and genetic heterogeneity (subjects with asthma caused by different genes).

\begin{tabular}{|c|c|c|c|}
\hline \multirow{2}{*}{$\begin{array}{l}\text { TABLE } 1 \\
\text { Candidate } \\
\text { genes }\end{array}$} & \multicolumn{3}{|c|}{ Risk factors for asthma } \\
\hline & $\begin{array}{l}\text { Positonal cloned genes } \\
\text { (chromosome) }\end{array}$ & Environment & $\begin{array}{l}\text { Personal } \\
\text { factors }\end{array}$ \\
\hline IL4 & ADAM33 (20p) & $\begin{array}{c}\text { Tobacco smoke } \\
\text { exposure }\end{array}$ & Sex \\
\hline II4RA & GPRA1 (7p) & Diet & Age \\
\hline IL13 & DPP10 (2q) & Pollutants & \\
\hline$T N F$ & PHD11 (13q) & Microbial products & \\
\hline LTA & $H L A-G(6 p)$ & & \\
\hline$B 2 A R$ & SFRS8 (12q) & & \\
\hline$H L A-D R$ and & CYF1P2 (5q) & & \\
\hline \multicolumn{4}{|l|}{$D Q$} \\
\hline \multicolumn{4}{|l|}{ CD14 } \\
\hline \multirow[t]{3}{*}{ FCERIB } & Whole genome & & \\
\hline & association & & \\
\hline & ORMDL3 (17q) & & \\
\hline
\end{tabular}

Twin studies suggest that $40-60 \%$ of asthma is caused by genetic factors. The number of genes contributing to asthma remains a matter of speculation, but based on the current evidence from linkage and association studies, it is likely that $\geqslant 30-100$ genes will be important in different populations. Several studies have been published that provide a comprehensive review of asthma genetics $[2,18]$.

It is most likely that asthma genes do not confer risk for asthma autonomously. The effects of a specific gene will rather depend on other genes and environmental exposures. The first example of a gene-gene interaction in asthma was shown in a Dutch study of asthmatic adult patients and their spouses, which investigated gene variants (alleles) in IL13 and IL4RA. Carriers of risk alleles in either IL13 or IL4RA had a modestly increased risk of asthma (odds ratio (OR) 1.85 and 1.83, respectively), whereas subjects with risk alleles in both genes had an increased OR of 4.83 (95\% confidence interval (CI) 2.011.9) of developing asthma [19]. In that study, IL4RA and IL13 had an additive effect.

Gene by environmental interaction in asthma is a likely interpretation of the results from a study in farmers' children living in Germany, Austria and Switzerland. Prevalence rates of asthma and allergies were reported to be lower in children living on farms than in children from rural populations not living on farms. It has been hypothesised that contact with microbial products, such as endotoxin, modifies the immune response and asthma development [20]. Important receptors for microbial products are Toll-like receptors (TLR), in particular TLR2 and TLR4. EDER et al. [21] showed that farmers' children carrying a T-allele in TLR2/-16934 were significantly less likely to have a diagnosis of asthma than farmers' children with genotype AA ( 3 versus $13 \%$; $\mathrm{p}=0.012$ ). This indicates that the environment (i.e. living on farms) modifies the association between the TLR2 gene and asthma. In other words, no association of TLR2 gene variants and asthma was observed in children not raised on farms [21].

Therefore, asthma is an example of a genetically complex disease, with multiple genes that may act additively and increase each other's effect by gene-gene and gene-environment interactions. Thus, any method to predict asthma should take into account the complexity of these interactions.

\section{PREDICTING ASTHMA IN CHILDHOOD}

Predicting asthma in early childhood remains one of the most difficult challenges in daily clinical practice; this is illustrated by the following case. A 2-yr-old male enters his doctor's practice complaining of intermittent wheezing and cough during the previous 4 months. According to his mother, he continuously suffers from a runny nose with episodes of fever since he started attending day care aged 1 yr. The child did not have eczema at infancy. One of the child's grandmothers has asthma and his mother has hay fever. The father smokes but not, it was assured, in the presence of the child.

Does this child have asthma? Is prescription of inhaled corticosteroids beneficial for this child? One may consider making an assumption based on epidemiological studies that have identified several risk factors for childhood asthma, i.e. family history, male sex, maternal smoking during pregnancy, 
atopy and the presence of infant eczema [22]. Their predictive value for asthma development will be discussed shortly.

Family history of asthma is an important risk factor for asthma in an individual. However, a familial aggregation of asthma may be due to both effects of shared genes and shared environmental factors. In 10 published studies, family history had positive predictive values (i.e. the proportion of patients with positive test results that were correctly diagnosed) ranging $11-37 \%$, whereas the negative predictive values (i.e. the proportion of subjects with negative test results that were correctly diagnosed) ranged $86-97 \%$ [23]. Thus, a family history of asthma is not a strong predictor of asthma in a child, yet the absence of a family history is a good predictor that the child will not develop asthma.

Clinical scores that use symptoms and clinical tests next to family history seem to provide better prognostic values for asthma than family history alone. One clinical score has been developed based on the data of the Tucson Children's Respiratory Study [22]. This was a prospective study from birth onwards that assessed, at 3 yrs of age, which factors are associated with doctor diagnosed asthma at 6-13 yrs of age. A clinical score for the prediction of asthma includes two major criteria (family history of asthma in one of the parents and doctor-diagnosed eczema in the child) and three minor criteria (doctor-diagnosed allergic rhinitis in the child, wheezing apart from colds, and blood eosinophilia at age $10 \mathrm{yrs}$ ). For a "stringent index", children had to have reported early frequent wheezing during the first 3 years of life, in addition to one of the two major criteria and two of three minor criteria. This stringent index had a positive predictive value ranging $42.0-51.5 \%$ for asthma at age 6-13 yrs, and a negative predictive value ranging $84.2-91.6 \%$ [22]. It appears that this index may improve the ability to predict asthma at school age in this population raised in Tucson (AZ, USA), whereas the negative predicative value is comparable to the presence of a family history of asthma. A drawback of the Tucson Children's Respiratory Study [22] is that the blood eosinophil data were collected at age $10 \mathrm{yrs}$ not at age 3 yrs, thus not allowing an initial set of data for risk assessment. Other studies have proposed similar scoring systems with comparable results for asthma or symptoms associated with asthma, such as persistent wheeze [24, 25]. The question arises as to whether genetic information will further increase the ability to predict asthma.

\section{GENETIC TESTING}

A genetic test has been defined as "the analysis of human DNA, RNA, chromosomes, proteins and certain metabolites in order to detect heritable disease-related genotypes, mutations, phenotypes or karyotypes for clinical purposes" [26]. In the present review, only DNA was analysed.

Two factors determine the predictive value of a genetic test for a disease with a given population prevalence: genotype relative risk (GRR) and allele frequency. GRR is defined as the ratio of disease risks between those with and those without the susceptibility genotype (comparable to an OR). What is the purpose of risk profiling the GRR of asthma genes in an individual? In the literature, results of association studies have not consistently been expressed as GRR. Therefore, the present authors reviewed published data on two of the best replicated candidate genes for asthma: IL13 and IL4RA. The results of these studies were expressed as GRR, and a strict definition was employed, i.e. the same SNP, the same allele, the same genetic model (i.e. codominant or recessive) and the same phenotype (asthma) were required for a definition of replication [27]. The current study was limited to investigations of asthma in Western, Caucasian case-control populations (table 2). Table 2 shows that the GRR of SNPs in IL4RA and IL13 is generally found to be 1.0-3.2 with some studies estimating even higher risk estimates (range 0.49-7.27). This risk estimation is in concordance with a meta-analysis of eight populations performed on $A D A M 33$, which showed that the best associated SNP (ST+7) had an OR of 1.46 (95\% CI 1.211.76) for asthma development [39]. Results from GWA studies in asthma and other complex diseases show that the GRR for genes identified through GWA is between 1.05-1.8 [12, 40].

However, the GRRs summarised in table 2 may be overestimated. In complex diseases, estimation of the effect size of the genotype has been shown to differ between small and large studies, with small studies generally reporting a higher genotype effect than large studies [41]. One reason for this may be population selection; if families are selected with multiple affected individuals, the contribution of the genotype to the phenotype may be higher compared with its contribution in the general population. One example is familial breast cancer. When two genes associated with familial breast cancer were discovered, BRCA1 and -2, it was initially estimated that almost all carriers of the mutations in these genes would develop breast cancer. However, these calculations were based on families where multiple family members had breast cancer and segregating at the BRCA1 and BRCA2 locus. Subsequent population-based assessments showed a lower lifetime risk of disease $(\sim 60 \%)$ in carriers [42]. Therefore, given the fact that risk calculations of asthma genes in selected study groups are possibly biased, some of the GRRs in table 2 may be overestimated.

What is the allele frequency of the risk alleles of asthma genes in the general population? Based on the information obtained to date, the allele frequency of risk alleles varies considerably, i.e. between $10-85 \%$. Indeed, in some cases the prevalent allele appears to confer risk for asthma, as shown previously in a meta-analysis for ADAM33 [39]. In the meta-analysis of eight studies, the risk allele frequency for ST+7 G was $84.9 \%$ in the asthma population and $79.1 \%$ in the control population. Based on an estimated asthma prevalence of $8 \%$, this SNP can be attributed to $\sim 50,000$ asthma cases in the UK population. Thus, asthma appears to be a complex genetic disease associated with SNPs in genes with moderate-to-high allele frequency in the population, low penetrance but substantial population attributable risk.

\section{A SINGLE GENE TEST FOR ASTHMA?}

The positive predictive value of a single gene test for a complex disease, such as asthma, is limited. This has been illustrated by HoltzMAN and MARTEAU [43] (table 3) who assessed the relationship between GRR and allele frequency in order to predict a disease, as in this example, with a population frequency of $5 \%$ (table 3 ). The positive predictive value of a single gene test appears to be lower with higher risk allele 


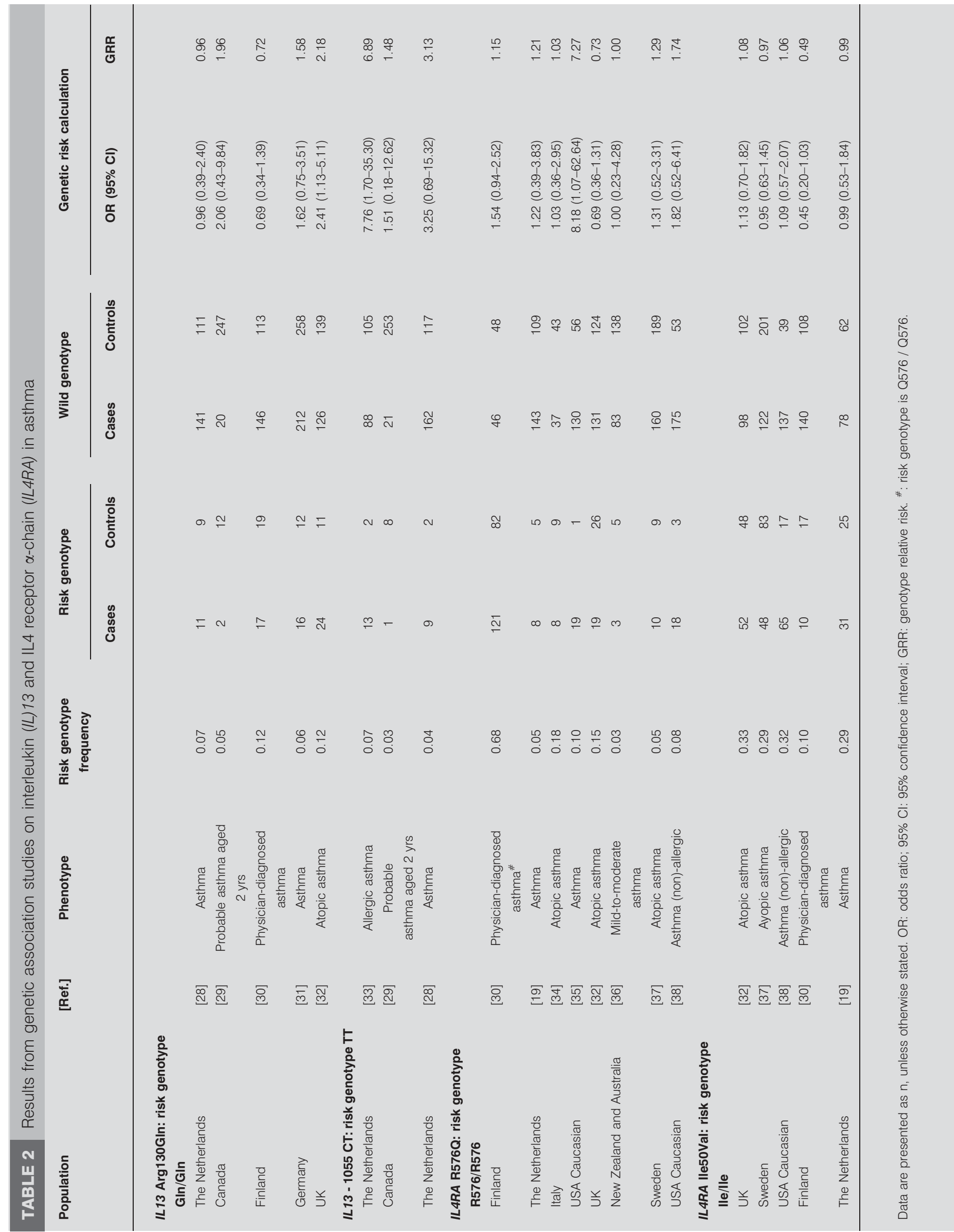




\begin{tabular}{|c|c|c|c|c|c|}
\hline TABLE 3 & $\begin{array}{l}\text { Positive pre } \\
\text { susceptibili } \\
\text { with a lifetir }\end{array}$ & $\begin{array}{l}\text { valu } \\
\text { ferrin } \\
\mathrm{x} \text { in a }\end{array}$ & $\begin{array}{l}\text { of te } \\
\text { enoty } \\
\text { ven } p\end{array}$ & $\begin{array}{l}\text { for } \\
\text { for a } \\
\text { lation }\end{array}$ & sease \\
\hline \multirow{2}{*}{$\begin{array}{l}\text { Risk genotype } \\
\text { frequency \% }\end{array}$} & \multicolumn{5}{|c|}{ Relative risk } \\
\hline & 1.5 & 2.0 & 5.0 & 10.0 & 20.0 \\
\hline 0.1 & 7.5 & 10.0 & 24.9 & 49.6 & 98.1 \\
\hline 0.5 & 7.5 & 10.0 & 24.5 & 47.8 & 91.3 \\
\hline 1.0 & 7.5 & 9.9 & 24.0 & 45.9 & 84.0 \\
\hline 10.0 & 7.1 & 9.1 & 17.9 & 26.3 & 34.5 \\
\hline 30.0 & 6.5 & 7.7 & 11.4 & 13.5 & 14.9 \\
\hline
\end{tabular}

frequencies and lower GRRs. Even with a GRR of 5.0, the presence of a disease susceptibility allele with an allele frequency of $30 \%$ results in a positive predictive value of $11.4 \%$ [43].

\section{MULTIPLE GENE TESTS FOR ASTHMA: GENETIC PROFILING}

Clearly, the complex nature of asthma is best reflected by tests that account for multiple genes. These tests have not been published for asthma to date, but results from simulation studies and other genetically complex diseases may illustrate its use.

Simulation studies express the usefulness of genetic testing as the area under the receiver operating characteristic curve (AUC), which reflects the combination of sensitivity and specificity. An AUC of 0.5 is nondiscriminatory. It is generally accepted that an AUC can be used for screening if it is $>0.8$, and can be used for pre-symptomatic diagnosis if $>0.99$. In a simulation study, YANG et al. [44] showed that a multiple gene test consisting of 20 genes with GRRs ranging 1.5-1.7 results in an AUC of 0.77. This figure is comparable to the predictive value of serum cholesterol levels for coronary heart disease. JANSSENS et al. [45] argued that lower GRRs and a higher number of genes are more realistic. Thus, they investigated the predictive value of genetic testing in relation to a gene number up to 400 using a multiplicative model, allele frequency, GRR and the heritability. Table 4 demonstrates that with 50 genes that relevant for disease development, an AUC of 0.8 can be reached if GRR is 1.5 and the risk allele frequency is $10 \%$. Moreover, JANSSENS et al. [45] demonstrated that excellent discrimination (AUC >0.95) is possible for complex genetic diseases with a prevalence $>1 \%$ and heritability of 0.23 ; this is compatible with the current authors' understanding of asthma with regards to heritability and disease prevalence. WRAY et al. [46] showed that GWA studies may be used to identify these genetic risk variants. For example, if a disease is controlled by 1,000 gene loci with a mean GRR of only 1.04, a case-control study with 10,000 cases and controls may lead to the selection of $\sim 75$ loci that control $>50 \%$ of the genetic variance of the disease [46]. A genome-wide study for asthma of this sample size is currently ongoing in Europe.

Two empirical studies into other genetically complex diseases may illustrate the predictive power of multiple gene tests.

First, YIANNAKOURIS et al. [47] have investigated the genetic contribution of 11 known risk genes to the incidence of coronary infarct in a Greek population. In total, 11 SNPs were investigated in a nested case-control study of 202 cases and 197 controls. A risk score was calculated for each individual by assigning a score of 1 if a subject was homozygous for the risk allele, and 0.5 for heterozygotes. These scores were added together for each gene up to a maximum score of 11 . For scores of $\geqslant 3$, the OR for coronary infarction development was 1.55 . For scores $\geqslant 3.5$, the OR increased to 2.02 . In these cases, $22 \%$ of the variance of the disease in the population could be explained by genetic risk factors [47]. The study by YIANNAKOURIS et al. [47] marks the first step towards the

TABLE 4 Multiple gene testing: effect of odds ratio (OR) and risk allele frequency

OR Risk allele frequency \% AUC of multiple test with 50 genes

\begin{tabular}{ccc}
\multicolumn{3}{c}{ Genes needed for AUC of: } \\
\hline $\mathbf{0 . 8 0}$ & $\mathbf{0 . 9 0}$ & $\mathbf{0 . 9 5}$ \\
$>400$ & $>400$ & $>400$ \\
$>400$ & $>400$ & $>400$ \\
$>400$ & $>400$ & $>400$ \\
$>400$ & $>400$ & $>400$ \\
$>400$ & $>400$ & $>400$ \\
$>400$ & $>400$ & $>400$ \\
320 & $>400$ & $>400$ \\
170 & $>400$ & $>400$ \\
80 & 240 & $>400$ \\
100 & 280 & $>400$ \\
50 & 150 & 330 \\
23 & 70 & 160
\end{tabular}




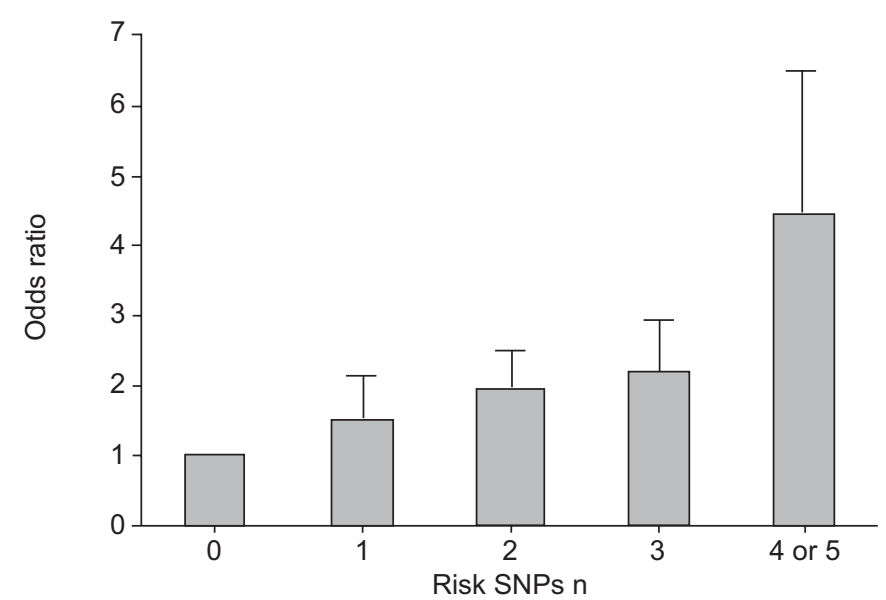

FIGURE 1. Odds ratio of the genetic risk for prostate cancer in relation to the number of risk genotype alleles in the Swedish population. SNP: single nucleotide polymorphisms.

analyses of multiple genes as predictive risk factors, even though there were several limitations, including: the fact that each gene had been attributed an equal risk; the fact that genegene interactions were not modelled [48]; and that over-fitting may limit the applicability of the results to other samples.

Secondly, ZHENG et al. [49] investigated SNPs from five chromosomal regions known to be associated with prostate cancer in a large Swedish case-control cohort of 2,893 patients and 1,781 controls. The five most significant SNPs, together with family history, were used to assess cumulative genetic risk for carriers of one to five risk alleles. When corrected for family history, having an increased number of risk SNPs significantly increased the prostate cancer risk (fig. 1). In a study subject with a positive family history, the prostate cancer risk was even higher and increased for carriers of one, two, three, four and five risk SNPs to 1.62, 2.07, 2.71, 4.76 and 9.46, respectively. There are several interesting aspects of this study. First, the functional role of these SNPs is not known, yet they can be used for risk prediction. Secondly, incorporating family history increased the predictive power of these risk SNPs. Thirdly, although the predictive power was higher in subjects carrying four out of five SNPs, this only accounted for $5.4 \%$ of the cases compared with $2.2 \%$ of the controls. Finally, these five SNPs, together with a family history, accounted for $46 \%$ of all prostate cancer cases in this population. Although these findings need to be assessed in a prospective study, they confirm that relevant risk SNPs can be assessed and used for genetic profiling [49].

\section{Combination of genes and personal factors}

The example of prostate cancer shows that combining risk SNPs with personal factors, including family history, may increase the predictive power of genetic profiling. Familial breast cancer may serve as an additional example. Two known breast cancer genes (BRCA1 and -2), and a third, hypothetical, gene were statistically modelled to investigate the predictive value of genetic tests. The cumulative risk of breast cancer for BRCA1 carriers was estimated to be 0.49 at 50 yrs of age and 0.71 at $70 \mathrm{yrs}$ of age, whereas the risk estimates for BRCA2 at the same

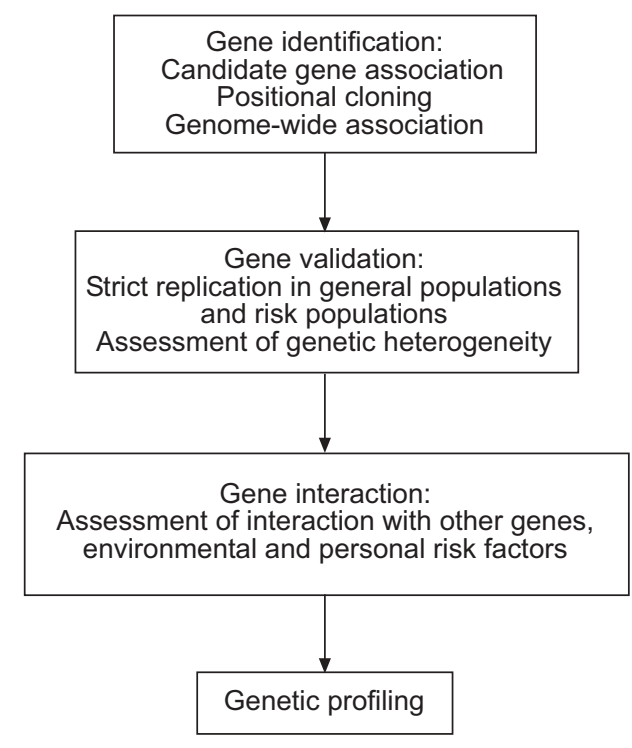

FIGURE 2. Flow diagram showing each stage from gene identification through to genetic profiling

ages were 0.28 and 0.84 , respectively. An interesting feature is that additional risk factors, such as parity, age at menarche, age at first child and body mass index, could be identified in a combined model and were found to increase predictive properties of the genetic tests. The present study has demonstrated that it is possible to predict risk of disease using a combination of genetic and personal information [50]. It should be noted that the penetrance of $B R C A 1$ and -2 is high compared with asthma genes but that the allele frequency is low.

\section{IMPLICATIONS FOR GENETIC TESTING OF ASTHMA}

To date, genetic testing for asthma is not possible and genetic tests for asthma that are currently available through the internet cannot be recommended [51]. The positive predictive value of single-gene tests is limited. First, genes for asthma need to be identified and strictly replicated for asthma (fig. 2). Secondly, investigations in other diseases show that disease prediction may be possible based on genetic profiling incorporating genes, personal factors and environmental risk factors. The predictive value of such a system will depend critically on the ability to model all these risk factors and to have large data sets available that are needed to validate these models. Furthermore, difference in the genetic make-up in different populations (genetic heterogeneity; for instance differences between Chinese and Caucasian populations) may seriously affect the ability to predict disease, and this should also be investigated [52]. Follow-up studies of general populations and risk groups, commencing before birth, should assess whether an approach based on multiple genetic tests that model personal and environmental factors has an increased positive predictive value compared with the current approaches.

\section{REFERENCES}

1 Koppelman GH. Gene by environment interaction in asthma. Curr Allergy Asthma Rep 2006; 6: 103-111. 
2 Ober C, Hoffjan S. Asthma genetics 2006: the long and winding road to gene discovery. Genes Immun 2006; 7: 95-100.

3 Van Eerdewegh P, Little RD, Dupuis J, et al. Association of the ADAM33 gene with asthma and bronchial hyperresponsiveness. Nature 2002; 418: 426-430.

4 Allen M, Heinzmann A, Noguchi E, et al. Positional cloning of a novel gene influencing asthma from chromosome 2q14. Nat Genet 2003; 35: 258-263.

5 Zhang Y, Leaves NI, Anderson GG, et al. Positional cloning of a quantitative trait locus on chromosome 13q14 that influences immunoglobulin E levels and asthma. Nat Genet 2003; 34: 181-186.

6 Brasch-Andersen C, Tan Q, Borglum AD, et al. Significant linkage to chromosome 12q24.32-q24.33 and identification of SFRS8 as a possible asthma susceptibility gene. Thorax 2006; 61: 874-879.

7 Noguchi E, Yokouchi Y, Zhang J, et al. Positional identification of an asthma susceptibility gene on human chromosome 5q33. Am J Respir Crit Care Med 2005; 172: 183-188.

8 Nicolae D, Cox NJ, Lester LA, et al. Fine mapping and positional candidate studies identify HLA-G as an asthma susceptibility gene on chromosome 6p21. Am J Hum Genet 2005; 76: 349-357.

9 Laitinen T, Polvi A, Rydman P, et al. Characterization of a common susceptibility locus for asthma-related traits. Science 2004; 304: 300-304.

10 Kormann MS, Carr D, Klopp N, et al. G-protein-coupled receptor polymorphisms are associated with asthma in a large German population. Am J Respir Crit Care Med 2005; 171: 1358-1362.

11 Melen E, Bruce S, Doekes G, et al. Haplotypes of G proteincoupled receptor 154 are associated with childhood allergy and asthma. Am J Respir Crit Care Med 2005; 171: 1089-1095.

12 Moffatt MF, Kabesch M, Liang L, et al. Genetic variants regulating ORMDL3 expression contribute to the risk of childhood asthma. Nature 2007; 448: 470-473.

13 Galanter J, Choudhry S, Eng C, et al. ORMDL3 gene is associated with asthma in three ethnically diverse populations. Am J Respir Crit Care Med 2008; 177: 1194-1200.

14 Tavendale R, Macgregor DF, Mukhopadhyay S, Palmer CN. A polymorphism controlling ORMDL3 expression is associated with asthma that is poorly controlled by current medications. J Allergy Clin Immunol 2008; 121: 860-863.

15 D'Amato G, Liccardi G, D'Amato M, Holgate S. Environmental risk factors and allergic bronchial asthma. Clin Exp Allergy 2005; 35: 1113-1124.

16 Upham JW, Holt PG. Environment and development of atopy. Curr Opin Allergy Clin Immunol 2005; 5: 167-172.

17 Koppelman GH. Gene-environment interaction in allergic disease: more questions, more answers? J Allergy Clin Immunol 2007; 120: 1266-1268.

18 Vercelli D. Discovering susceptibility genes for asthma and allergy. Nat Rev Immunol 2008; 8: 169-182.

19 Howard TD, Koppelman GH, Xu J, et al. Gene-gene interaction in asthma: IL4RA and IL13 in a Dutch population with asthma. Am J Hum Genet 2002; 70: 230-236.

20 Braun-Fahrlander C, Riedler J, Herz U, et al. Environmental exposure to endotoxin and its relation to asthma in schoolage children. N Engl J Med 2002; 347: 869-877.
21 Eder W, Klimecki W, Yu L, et al. Toll-like receptor 2 as a major gene for asthma in children of European farmers. J Allergy Clin Immunol 2004; 113: 482-488.

22 Castro-Rodriguez JA, Holberg CJ, Wright AL, Martinez FD. A clinical index to define risk of asthma in young children with recurrent wheezing. Am J Respir Crit Care Med 2000; 162: 1403-1406.

23 Burke W, Fesinmeyer M, Reed K, Hampson L, Carlsten C. Family history as a predictor of asthma risk. Am J Prev Med 2003; 24: 160-169.

24 Kurukulaaratchy RJ, Matthews S, Holgate ST, Arshad SH. Predicting persistent disease among children who wheeze during early life. Eur Respir J 2003; 22: 767-771.

25 Eysink PE, ter Riet G, Aalberse RC, et al. Accuracy of specific $\operatorname{IgE}$ in the prediction of asthma: development of a scoring formula for general practice. Br J Gen Pract 2005; 55: 125-131.

26 Burke W. Genetic testing. N Engl J Med 2002; 347: 18671875.

27 Holloway JW, Koppelman GH. Identifying novel genes contributing to asthma pathogenesis. Curr Opin Allergy Clin Immunol 2007; 7: 69-74.

28 Howard TD, Whittaker PA, Zaiman AL, et al. Identification and association of polymorphisms in the interleukin-13 gene with asthma and atopy in a Dutch population. Am J Respir Cell Mol Biol 2001; 25: 377-384.

29 He JQ, Chan-Yeung M, Becker AB, et al. Genetic variants of the IL13 and IL4 genes and atopic diseases in at-risk children. Genes Immun 2003; 4: 385-389.

30 Kauppi P, Lindblad-Toh K, Sevon P, et al. A secondgeneration association study of the $5 \mathrm{q} 31$ cytokine gene cluster and the interleukin-4 receptor in asthma. Genomics 2001; 77: 35-42.

31 Heinzmann A, Jerkic SP, Ganter K, et al. Association study of the IL13 variant Arg110Gln in atopic diseases and juvenile idiopathic arthritis. J Allergy Clin Immunol 2003; 112: 735-739.

32 Heinzmann A, Mao XQ, Akaiwa M, et al. Genetic variants of IL-13 signalling and human asthma and atopy. Hum Mol Genet 2000; 9: 549-559.

33 van der Pouw Kraan TC, van Veen A, Boeije LC, et al. An IL-13 promoter polymorphism associated with increased risk of allergic asthma. Genes Immun 1999; 1: 61-65.

34 Patuzzo C, Trabetti E, Malerba G, et al. No linkage or association of the IL-4R $\alpha$ gene Q576R mutation with atopic asthma in Italian families. J Med Genet 2000; 37: 382-384.

35 Rosa-Rosa L, Zimmermann N, Bernstein JA, Rothenberg ME, Khurana Hershey GK. The R576 IL-4 receptor $\alpha$ allele correlates with asthma severity. J Allergy Clin Immunol 1999; 104: 1008-1014.

36 Sandford AJ, Chagani T, Zhu S, et al. Polymorphisms in the IL4, IL4RA, and FCERIB genes and asthma severity. J Allergy Clin Immunol 2000; 106: 135-140.

37 Hytonen AM, Lowhagen O, Arvidsson M, et al. Haplotypes of the interleukin- 4 receptor $\alpha$ chain gene associate with susceptibility to and severity of atopic asthma. Clin Exp Allergy 2004; 34: 1570-1575.

38 Risma KA, Wang N, Andrews RP, et al. V75R576 IL-4 receptor $\alpha$ is associated with allergic asthma and enhanced IL-4 receptor function. J Immunol 2002; 169: 1604-1610. 
39 Blakey J, Halapi E, Bjornsdottir US, et al. Contribution of ADAM33 polymorphisms to the population risk of asthma. Thorax 2005; 60: 274-276.

40 Zeggini E, Scott LJ, Saxena R, et al. Meta-analysis of genome-wide association data and large-scale replication identifies additional susceptibility loci for type 2 diabetes. Nat Genet 2008; 40: 638-645.

41 Ioannidis JP, Trikalinos TA, Ntzani EE, ContopoulosIoannidis DG. Genetic associations in large versus small studies: an empirical assessment. Lancet 2003; 361: 567-571.

42 Elwood JM. Public health aspects of breast cancer gene testing in Canada. Part 1: risks and interventions. Chronic Dis Can 1999; 20: 3-13.

43 Holtzman NA, Marteau TM. Will genetics revolutionize medicine? N Engl J Med 2000; 343: 141-144.

44 Yang Q, Khoury MJ, Friedman J, Little J, Flanders WD. How many genes underlie the occurrence of common complex diseases in the population? Int J Epidemiol 2005; 34: 1129-1137.

45 Janssens AC, Aulchenko YS, Elefante S, Borsboom GJ, Steyerberg EW, van Duijn CM. Predictive testing for complex diseases using multiple genes: fact or fiction? Genet Med 2006; 8: 395-400.
46 Wray NR, Goddard ME, Visscher PM. Prediction of individual genetic risk to disease from genome-wide association studies. Genome Res 2007; 17: 1520-1528.

47 Yiannakouris N, Trichopoulou A, Benetou V, Psaltopoulou T, Ordovas JM, Trichopoulos D. A direct assessment of genetic contribution to the incidence of coronary infarct in the general population Greek EPIC cohort. Eur J Epidemiol 2006; 21: 859-867.

48 Janssens AC, van Duijn CM. Towards predictive genetic testing of complex diseases. Eur J Epidemiol 2006; 21: 869-870.

49 Zheng SL, Sun J, Wiklund F, et al. Cumulative association of five genetic variants with prostate cancer. $N$ Engl J Med 2008; 358: 910-919.

50 Tyrer J, Duffy SW, Cuzick J. A breast cancer prediction model incorporating familial and personal risk factors. Stat Med 2004; 23: 1111-1130.

51 Janssens AC, Gwinn M, Bradley LA, Oostra BA, van Duijn CM, Khoury MJ. A critical appraisal of the scientific basis of commercial genomic profiles used to assess health risks and personalize health interventions. Am J Hum Genet 2008; 82: 593-599.

52 Liu W, Icitovic N, Shaffer ML, Chase GA. The impact of population heterogeneity on risk estimation in genetic counseling. BMC Med Genet 2004; 5: 18. 